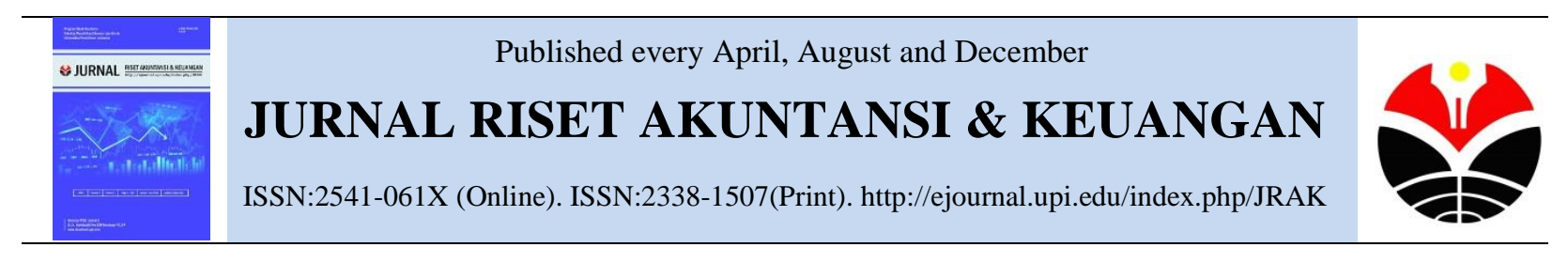

\title{
Analisis Kelayakan Finansial Wisata Air Waduk Jatigede Kabupaten Sumedang
}

\author{
Bambang Susanto ${ }^{1}$, Sukadwilinda ${ }^{2}$ \\ ${ }^{1}$ Program Studi Akuntansi, Fakultas Ekonomi, Universitas Sangga Buana-YPKP, Bandung, Indonesia \\ ${ }^{2}$ Program Studi Akuntansi, Fakultas Ekonomi, Universitas Sangga Buana-YPKP, Bandung, Indonesia
}

\begin{abstract}
Sumedang regency is one of the 26 regency in West Java. Sumedang is a district of the capital of West Java, which has a wide range of culture and tourism. Culinary tourism especially know already known nationally. To further develop other tourist tours in Sumedang district need to do breakthrough one of the breakthrough by exploiting the existing potential. Jatigede reservoir,in addition to its designation for hydroelectric power and irrigation, jatigede reservoir can also be developed towards the tour of water tourism. Development of water tourism area in order to provide benefits for the surrounding community, of course, need to do preliminary studies for the benefits far greater than the cost incurred. Therefore, for scientific purposes, it is necessary to conduct an academic study in the form of Financial Feasibility Analysis. Based on the analysis of financial feasibility, it can be concluded that water tourism in Jatigede Reservoir Sumedang have benefits. It's the results of a positive net prese nt value analysis, internal rate of return greater than the interest rate of banks and benefit cost greater than on.
\end{abstract}

Keywords: Financial Feasibility; Water Tour.

Abstrak. Kabupaten Sumedang merupakan salah satu dari 26 Kabupaten Kota yang ada dipropinsi Jawa barat. Sumedang merupakan kabupaten penyangga Ibu kota propinsi Jawa barat, yang memiliki beraneka ragam budaya dan wisata. Wisata kuliner terutama tahu sudah dikenal secara nasional. Untuk lebih mengembangkan wisata wisata lain yang ada di kabupaten Sumedang tentunya perlu dilakukan terobosan terobosan salah satunya dengan memanfaatkan potensi yang ada. Waduk jatigede salah satunya, selain peruntukannya untuk pembangkit listrik tenaga air dan kepentingan irigasi, waduk jatigede juga dapat dikembangkan kearah wisata yaitu wisata air. Pembangunan kawasan wisata air agar dapat memberikan manfaat bagi masyarakat sekitar, tentunya perlu dilakukan studi pendahuluan agar manfaatnya jauh lebih besar dari biaya yang dikeluarkan. Oleh sebab itu untuk kepentingan ilmiah perlu dilakukan kajian akademisnya berupa Analisis kelayakan Finansial. Berdasarkan analisis kelayakan keuangan ,dapat disimpulkan bahwa wisata air di Waduk jatigede Kabupaten Sumedang memberikan manfaat yang lebih dibandingkan dengan biaya yang dikeluarkan . ini dapat dilihat dari hasil analisis net present value yang positif, internal rate of return yang lebih besar dari tingkat bunga bank serta benefit cost yang lebih besar dari satu.

Kata Kunci: Kelayakan Finansial; Wisata Air.

Corresponding author. Email: ${ }^{1}$ Bambangsusanto18@gmail.com, ${ }^{2}$ Sukadwilinda@gmail.com

How to cite this article. Bambang Susanto, S. (2016). Analisis Kelayakan Finansial Wisata Air Waduk Jatigede Kabupaten Sumedang. Jurnal Riset Akuntansi Dan Keuangan. Program Studi Akuntansi. Fakultas Pendidikan Ekonomi Dan Bisnis Universitas Pendidikan Indonesia, 4(1), 867-872. Retrieved from http://ejournal.upi.edu/index.php/JRAK/article/view/7707

History of article. Received: January 2016, Revision: Maret 2016, Published: April 2016

Online ISSN: 2541-061X. Print ISSN: 2338-1507. DOI : 10.17509/jurnal jrak.v4i1.7707

Copyright@2016. Jurnal Riset Akuntansi dan Keuangan Program Studi Akuntansi FPEB UPI 


\section{PENDAHULUAN}

Waduk Jatigede merupakan bagian wilayah sungai Cimanuk-Cisanggarung mencakup daerah aliran sungai Kab.Garut, Sumedang, Majalengka, Cirebon, Inderamayu, Kuningan serta Brebes Jawa Tengah. Waduk Jatigede terletak di Kampung Jatigede Kulon Desa Cijeungjing Kecamatan Jatigede Kabupaten Sumedang. Waduk Jatigede memiliki luas 4.891,13 ha yang meliputi 5 (lima) Kecamatan yaitu : Kec Jatigede, Kec Jatinunggal, Kec Wado, Kec. Darmajaya dan Kec Cisitu serta 26 (Dua puluh enam) Desa . Peruntukan utama adalah untuk Pembangkit listrik Tenaga Air, Irigasi Pertanian dan 654,84 Ha atau 1,45\% (Data : RT RW Kab Sumedang) pemanfaatan untuk Kawasan Pengembangan Pariwisata. Pengembangan wisata yang sesuai dengan adanya Waduk Jatigede adalah wisata air (water Sport). Dampak dan manfaat suatu proyek tentunya akan dirasakan oleh masyarakat sekitarnya, oleh sebab itu pemanfaatan waduk selain untuk kebutuhan pertanian, wisata tentunya tidak kalah penting mengingat Sumedang merupakan daerah penyangga Ibu Kota Propinsi Jawa Barat yang tentunya selain wisata kuliner yang ditawarkan Kabupaten Sumedang juga ada pilihan lain yaitu wisata air dengan memanfaatkan Waduk Jatigede

\section{KAJIAN LITERATUR}

Kajian yang sifatnya menyeluruh dan mendalam segala aspek kelayakan proyek dikenal dengan istilah studi kelayakan. Studi kelayakan harus dapat menyuguhkan hasil analisis secara kuantitatif tentang manfaat yang akan diperoleh dibandingkan dengan sumber dana yang diperlukan. Aspek-aspek studi kelayakan yang perlu ditinjau antara lain aspek teknis, aspek manajemen operasional, aspek ekonomi dan finansial dan lain sebagainya. Aspek Finansial merupakan aspek utama tentang perbandingan antara pengeluaran dengan pemasukan uang (return) dalam suatu proyek. Dalam pengkajian aspek finansial digunakan aliran kas (Cash Flow) sebagai model, selanjutnya dengan menganalisis aliran kas tersebut dengan memakai metode dan kriteria yang dipakai secara luas untuk memilah-milah mana yang dapat diterima dan mana yang akan ditolak. Maksud dan tujuan studi kelayakan adalah agar proyek yang layak yang dapat dilanjutkan karena terbatasnya sumber-sumber yang tersedia dan dapat dipertanggung jawabkan secara finansial.

Dalam aspek finansial menurut Adler (2008) tujuan dari analisis finansial adalah apakah suatu proyek secara finansial mampu untuk hidup, apakah mampu untuk memenuhi kewajiban kewajiban finansialnya dan bisa menghasilkan imbalan yang layak atau modal yang diinvestasikan dapat kembali. Didalam analisis finansial selalu digunakan harga pasar untuk mencari nilai sebenarnya dari barang dan jasa dimana dalam analisis ditekankan adalah Privat and Return dari beberapa komponen seperti biaya, pendapatan dan tingkat suku bunga.

Komponen pertama yaitu biaya. Menurut Kodoatie , biaya dikelompokkan menjadi biaya modal (capital cost) yaitu jumlah semua pengeluaran yang dibutuhkan mulai dari dari prastudi sampai proyek selesai dibangun dan biaya tahunan yaitu biaya yang masih diperlukan sepanjang umur proyek. Biaya tahunan terdiri dari yang pertama yaitu suku bunga, suku bunga akibat terjadinya perubahan biaya modal karena adanya tingkat suku bunga selama umur proyek. Biaya bunga ini merupakan yang terbesar yang diperhitungkan terhadap modal. Kedua adalah depresiasi atau amortiasi, depresiasi adalah turunya atau penyusutan suatu harga atau nilai dari sebuah benda karena pemakaian sedangkan amortiasi adalah pembayaran dalam suatu periode tertentu (tahunan) sehingga hutang yang ada akan terbayar lunas. Dan yang ketiga yaitu biaya operasi dan pemeliharaan, agar umur proyek dapat dipenuhi sesuai dengan yang direncanakan, maka diperlukan biaya operasi dan pemeliharaan. Investasi pada hakekatnya adalah penempatan sejumlah dana pada saat ini dengan harapan untuk memperoleh keuntungan dimasa mendatang. Investasi yang dimaksudkan 
pada penelitian ini adalah Investasi Pembangunan Sarana dan Prasarana Wisata Air (water Sport) Waduk jatigede Kab. Sumedang.

Komponen kedua adalah pendapatan. Biaya produksi bervariasi langsung dengan perubahan volume produksi, sedangkan biaya lainnya relatif tidak berubah terhadap jumlah produksinya. Oleh karena itu manajemen perlu memperhatikan beberapa kecenderungan biaya tersebut untuk dapat merencanakan dan mengendalikan efek biaya terhadap volume produksi (Giatman, 2006). Selain sebagai bagian integral dari proses belajar mengajar, ruang kuliah atau gedung perkuliahan merupakan bagian penting komponen penunjang pendapatan / benefit.

Komponen ketiga adalah bunga. Bunga (interest) adalah sejumlah uang yang dibayarkan akibat pemakaian uang pinjaman sebelumnya. Besarnya bunga adalah selisih antara jumlah hutang yang dibayar dengan utang semula. Atau Bunga sama dengan jumlah utang sekarang dikurangi jumlah pinjaman semula.Tingkat suku bunga merupakan rasio antara bunga yang dibebankan per periode waktu dengan jumlah uang yang dipinjam awal periode dikalikan $100 \%$. Bunga ini terjadi dikarenakan adanya konsep nilai uang terhadap waktu, dimana nilai uang berubah bersamaan dengan perubahan waktu.

Secara analisis finansial cash flow adalah anggaran kas (cash budget). Arus uang yang masuk dan yang keluar menandakan adanya suatu kegiatan. Arus uang yang masuk dan keluar harus selalu diupayakan keseimbangannya. Bila salah satu berhenti, maka kegiatannya juga akan berhenti atau bisa saja berhenti. Sementara yang tertunda baik disengaja maupun tidak disengaja dalam batas - batas kemampuan pihak-pihak yang terlibat. Cash Flow adalah alat pengendali likuiditas yang selalu mengupayakan agar kondisi keuangan tidak defisit atau walaupun menurut program kerja harus defisit diupayakan sekecil mungkin dan dapat segera diatasi untuk berubah menjadi surplus (Suharto, 1995).
Dalam analisis finansial ada beberapa kriteria yang digunakan dalam menentukan diterima atau tidaknya suatu usulan investasi. Penentuan kriteria didasarkan pada manfaat (benefit), maupun biaya (cost), dan dinyatakan dalam nilai sekarang (Present Net Vlue).Masing masing kriteria peniliaian mempunyai keunggulan dan kelemahan (Giatman, 2006). Terdapat beberapa metode dalam mengevaluasi kelayakan investasi yang umum dipakai antara lain : Metode $\mathrm{Net}$ Present Value (NPV), Metode Annual Equivalent (AE), Metode Internal Rate of Return (IRR), Metode Benefit Cost Ratio (BCR) dan Metode Payback Period (PBP).

Memaparkan tentang telaah dari berbagai referensi yang bersumber dari buku ilmiah umum, buku-buku teoritis, skripsi, tesis, disertasi dan jurnal ilmiah dan erat hubungannya dengan penelitian, penelitian sebelumnya berkaitan dengan judul penelitian , hipotesis penelitian yang dituliskan dalam paragraf mengalir.

\section{METODOLOGI PENELITIAN}

Metode yang digunakan dalam penelitian ini adalah metode Deskriftif komparatif dengan metode pungumpulan datanya melalui survey lapangan yang menghasilkan data primer dan skunder. Sedangkan alat analisisnya dengan menggunakan kriteria investasi dengan Metode Net Present Value (NPV), Metode Annual Equivalent (AE), Metode Internal Rate of Return (IRR), Metode Benefit Cost Ratio (BCR) dan Metode Payback Period (PBP).

Pada dasarnya penggunaan semua metode tersebut konsisten satu sama lain artinya jika dievaluasi dengan metode NPV dan metode lainnya akan menghasilkan rekomendasi yang sama, tetapi informasi spesifik yang dihasilkan tentu akan berbeda. Oleh karena itu dalam prakteknya masingmasing metode sering dipergunakan secara bersamaan dalam rangka mendapatkan gambaran yang lebih komprehensif terhadap perilaku investasi tersebut.

Metode Payback Period pada dasarnya bertujuan untuk mengetahui seberapa lama 
investasi akan dapat dikembalikan saat terjadinya kondisi break event point. Metode Annual Equivalent konsepnya kebalikan dari NPV (seluruh aliran cash ditarik dalam bentuk present), dimana aliran cash akan didistribusikan secara merata pada periode sepanjang umur investasi. Hasil distribusi yang merata menghasilkan pendapatan per tahun atau Annual Equivalent (AE).

Net Present Value (NPV) menghitung selisih antara nilai sekarang suatu investai dengan nilai sekarang penerimaanpenerimaan kas bersih di masa yang akan datang. Untuk menghitung nilai sekarang perlu ditentukan dulu tingkat bunga yang dianggap relevan. Apabila nilai sekarang penerimaan penerimaan kas yang akan datang lebih besar dari nilai sekarang investasi, maka keadaan ini dikatakan menguntungkan/ diterima, namun jika lebih kecil maka investasi tersebut ditolak (Giatman, 2006).

Benefit Cost Ratio Merupakan perbandingan ntara manfaat bersih dari tahun yang bersangkutan yang telah dinilai sekarang, Dalam kriteria ini dibedakan tahun-tahun dimana terdapat net benefit yang positif dan tahun-tahun dimana net benefit bersifat negatif. Jadi benefit Cost Ratio adalah Net Benefit Positif dibagi Net Benefit Negatif (Giatman, 2006).

Internal rate of Return adalah tingkat suku bunga (discount rate) yang dapat membuat harga NPV dari suatu nilai proyek bernilai 0 , atau BC Ratio sama dengan 1 (satu). Dalam perhitugan IRR, diasumsikan bahwa setiap benefit netto tahun secara otomatis ditanam kembali dalam tahun berikutnya, dan memperoleh Rate of Return yang sama dengan investasi sebelumnya. Besar IRR dicari dengan metode Trial and Error, pertama ditetapkan satuan "i" yang diperlukan mendekati IRR. Jika nilai perhitungan memberikan nilai NPV yang negatif berarti sudah lebih besar dari IRR, kalau hal ini sudah dicapai, selanjutnya diadakan interpolasi antara discount rate yang tertinggi (masih memberikan nilai positif) dan discount rate yang rendah yang memberikan nilai NPV negatif sehingga nilai yang diperoleh sebesar 0. Kriteria IRR ini memberikan pedoman bahwa usaha yang akan dipilih dapat diterima apabila lebih besar dari tingkat suku bunga yang berlaku (IRR $\geq$ i) dan apabila IRR lebih kecil dari tingkat suku bunga, maka usaha tersebut tidak layak dilakukan.

Perubahan-perubahan dan fluktuasi harga dapat diabaikan dan tidak akan mengubah keputusan evaluasi yang diambil sebelumnya. Batasan nilai perubahan tersebut yang akan mampu merubah kembali keputusan sebelumnya disebut dengan dengan tingkat sensitivitas dari parameter yang diuji.

\section{HASIL DAN PEMBAHASAN}

Dalam penyusunan analisis kelayakan finansial wisata air di waduk jatigede dipakai beberapa asumsi asumsi yang didasarkan kondisi eksisting di objek penelitian maupun data sekunder yang diperoleh dari objek wisata sejenis seperti yang akan dikembangkan di waduk jatigede. Dalam penyusunan studi kelayakan finansial wisata air di waduk jatigede diawali dengan penyususnan rencana investasi, dan dibuat prakiraan pendapatan dan pengeluaran dari objek wisata air jatigede, serta dibuat cash flow. Tabel hasil penelitian terlampir

Hasil analisis finansial dalam penelitian ini didapatkan bahwa bahwa : Analisa Net Present Value (Npv) : Npv $=190,002,990$. Analisa NPV Ternyata NPV > 0 pada Df (Suku Bunga) 15\%, berarti proyek tersebut menguntungkan dan layak untuk diusahakan.

Analisa Net Benefit Cost Ratio (Net B/C) : NET B/C=32.10. Karena Net B/C-Nya lebih besar dari satu, maka benefit yang diperoleh itu : tiga puluh dua kali lipat dari Cost yang dikeluarkan, maka proyek wisata Air (Water Sport) Itu layak untuk diusahakan.

Analisa Internal Rate Of Returnnya Sebesar (Irr) : $16.94 \%$. Artinya proyek wisata Air Jatigede ini jika dilakukan menghasilkan Return sebesar 16.94\% Atau 1,94\% lebih besar jika investasi dilakukan disektor Perbankan. 


\section{SIMPULAN}

Berdasarkan analisis kelayakan keuangan dengan menggunakan beberapa metode pendekatan ,dapat disimpulkan bahwa wisata air di waduk jatigede kabupaten sumedang memberikan manfaat yang lebih dibandingkan dengan biaya yang dikeluarkan. Ini dapat dilihat dari hasil analisis net present value yang positif, internal rate of return yang lebih besar dari tingkat bunga bank serta benefit cost yang lebih besar dari satu.

\section{DAFTAR PUSTAKA}

Sartono, A. (. (2000). Manajemen Keuangan Teori dan Aplikasi. Yogyakarta: BPFE Yogyakarta.

Giatman. (2006). Ekonomi Teknik. PT Raja Grafindo Persada.

Scott, David., JR, et all. (1999). Basic Financial Management, Eigth Edition, Prentice Hall International, Inc. New Jersey.

Sumastuti. (2005). Pengambilan Keputusan Investasi Melalui Capital Budgeting Jurnal Ilmiah \& Bisnis.

Kodiatie. (2010). Analisis Dampak Investasi Pada Industri Pulp \& Kertas Terhadap kesempatan kerja \& pendapatan rumah tangga Indonesia. Universitas Diponegoro. 
Tabel 1. Biaya Operasional Gaji Personil

\begin{tabular}{clcccc}
\hline & \multicolumn{1}{c}{ Item Biaya } & Orang/bulan & Gaji/bulan & Jumlah/bulan & Keterangan \\
\hline I & Professional Staf & 3 & $4,000,000$ & $12,000,000$ & No Overtime \\
1 & Dewan Direksi & & & & \\
& & & & \\
II & Sub Professional Staf & 23 & $1,000,000$ & $23,000,000$ & Insentive \\
1 & Staf Pelaksana Harian & & & & \\
& (Staf Harian: 3 org, & & & & \\
& SATPAM: 10 org, & & & \\
& Kebersihan: 10 org) & & $35,000,000$ & \\
\hline
\end{tabular}

Tabel 2. Biaya Operasional Bulanan Kantor

\begin{tabular}{clccc}
\hline No. & \multicolumn{1}{c}{ Item Biaya } & Jumlah Bulan & Biaya / bulan & Keterangan \\
\hline 1 & Telepon & Jumlah Bulan & 250,000 & Asumsi \\
2 & ATK & 1 & 250,000 & Asumsi \\
3 & Listrik Kantor & 1 & 250,000 & Asumsi \\
5 & Transport Lokal & 1 & 350,000 & Asumsi \\
6 & Insentive & 1 & 500,000 & Asumsi \\
7 & Pemeliharaan Rutin & 1 & 500,000 & Asumsi \\
& & & $2,100,000$ & \\
\hline
\end{tabular}

Tabel 3 Biaya Operasional Bulanan Wisata Air

\begin{tabular}{crrrc}
\hline No. & Item Biaya & Jumlah Bulan & Biaya / bulan & Keterangan \\
\hline 1 & Sampan & 1 & $1,000,000$ & Asumsi \\
& & & $1,000,000$ & \\
\hline
\end{tabular}

Tabel 5 Depresiasi

\begin{tabular}{ccc}
\hline Uraian & Tahun Ke- & Depresiasi / Tahun \\
\hline DEPRESIASI BANGUNAN, (5 Tahun) & 1 & $1,363,992,000.00$ \\
& 2 & $1,363,992,000.00$ \\
& 3 & $1,363,992,000.00$ \\
TOTAL DEPRESIASI & 4 & $1,363,992,000.00$ \\
& 5 & $1,363,992,000.00$ \\
& & $6,819,960,000.00$ \\
\hline
\end{tabular}

